\title{
Endogent: Centre for Anatomy and Invasive Techniques
}

\author{
Ingrid Kerckaert $^{1}$, Tom Van Hoof ${ }^{1}$, Piet Pattyn ${ }^{2}$, Katharina D'Herde ${ }^{1}$ \\ ${ }^{1}$ Department of Anatomy, Embryology, Histology and Medical Physics, Gent, Belgium \\ ${ }^{2}$ Department of Surgery, University Hospital Ghent, Gent, Belgium
}

\begin{abstract}
The invention of new endoscopical techniques for surgery and interventional radiology demand improved training at postgraduate level. The Endogent Centre for Anatomy and Invasive Techniques support these requirements by establishing hands-on practical training courses by using new procedures for cadaver embalming. Cadavers fixed by conventional procedures using formalin for conservation, are of limited use for practical surgical courses due to the profound changes of colour, strength and fragility of organs and tissues. The new Thiel embalming technique is based on the use of 4-chloro-3methylenphenol, various salts for fixation, boric acid for disinfecting, and ethylene glycol for preservation of tissue plasticity, while the concentration of formalin is kept to the strict minimum $(0.8 \%)$. This results in well preserved organs and tissues concerning colour, consistency, flexibility and plasticity. The articular joints remain freely movable and the peritoneal cavity can be inflated for laparoscopic procedures. Up to now this cadaver model was used in our institute for laparoscopic bariatric surgery, colon surgery, arthroscopy and thorax surgery. Another feature is that the lungs can be ventilated during surgical procedures. Preliminary findings seem to indicate that the corpses also serve as a suitable phantom for assessing thorax radiological equipment. Expert clinicians work as tutors and give intensive instructions before the participants start with hands-on surgery. We intend to expose also our undergraduate medical students to demonstrations of surgical approaches on Thiel embalmed corpses, in order to reveal the need for detailed anatomical knowledge in the clinic at an early stage in the medical curriculum.
\end{abstract}

Key words: endoscopy; Thiel embalming technique; gross anatomy; postgraduate teaching

Anatomy 2008; 2: 28-33, @ 2008 TSACA

\section{Introduction}

Gross anatomy is one of the fundamental topics in medical education. Dissection courses still play an important role in learning it, as well in undergraduate as in postgraduate education. In addition new endoscopical techniques for surgery and interventional radiology are invented and demand improved training at postgraduate level.

The Endogent Centre for Anatomy and Invasive Techniques at the Ghent University support these requirements by establishing hands-on practical training courses by using new procedures for cadaver embalming.
This new approach is introduced by Endogent, which is a cooperation and a collaboration between the surgeryanaesthesia department (Commission of Surgery) of the University Hospital Ghent and the department of anatomy, embryology, histology and medical physics (University Ghent).

It is used for training techniques in postgraduate education: workshops for international surgeons and aspirant-surgeons are organized to learn already known and new invasive techniques on human bodies. In the future also undergraduate medical students will have the opportunity to get practical experience through Endogent. 
The new procedure for cadaver embalming is the Thiel-embalming method, through which the corpses, tissues and the organs retain their flexibility and plasticity as in a living person and the articular joints remain freely movable. The colour of the organs is very similar to the in vivo condition. Only no bleedings occur.

\section{History}

Prof. Em. Walther Thiel, Anatomisches Institut Karl-Franzens-Universität, Graz, Austria, developed the new embalming technique and published his method in 1992, ${ }^{1}$ he wrote: "An especially low-odour embalming technique was developed over a 30 -years-period using a total of 977 complete cadavers, numerous cadavers after autopsy, and in vitro series of fresh beef. The colour, consistency and transparency of the tissue were very well preserved. The technique met high standards of preservation without releasing harmful substances into the environment. Concentrations of formaldehyde in room air remained under the limit of detection. The efficacy for disinfection of the method was confirmed by bacteriologic tests. None of the cadavers or samples developed moulds."

This technique was used at the University of Fribourg, Switzerland, where a comparable centre as should become Endogent was already active: there the centre is called Swissendos, a multidisciplinary research and training centre in endoscopic surgery.

Morand et al. ${ }^{2}$ (Fribourg, Switzerland) wrote as follows. "The technique allows a floppy preservation of human tissue similar to that found in living counterparts. Our centre organizes courses for endoscopy, thoracic surgery, bariatric, antireflux, abdominal wall, colon and rectum surgery. Video monitors with camera system are available with the possibility of computerized image recording".

They concluded "that endoscopic and thoracoscopic training on cadavers outside the operating theatre is necessary for surgeons to perform operations; difficult endoscopical and surgical procedures can be taught step by step under real anatomic situations in small groups".
A delegation of the future Endogent centre twice visited the University of Fribourg in 2005 to follow a demonstration and to learn the Thiel-embalming technique.

In the summer of 2006 the Ghent Centre was officially opened as the second in Europe. Workshops are organized for people all over the world. Both clinicians and anatomists are closely working together.

So Endogent is one of the few centres all over the world in which the embalming technique of Thiel is used: the human cadavers are preserved in a better way as is needed for practising operation techniques on post mortem human bodies.

\section{Materials and Methods}

\section{Conventional procedure for embalming human corpses}

Cadavers fixed by conventional procedures by using (a lot of) formalin for conservation are of limited use for practical surgical courses due to the profound changes of colour, strength and fragility of organs and tissues.

\section{A. Embalming solution as normally used in the} Ghent Anatomy Department

\begin{tabular}{lc} 
chloralhydrate & $2500 \mathrm{gr}$ \\
sodiumsulfate & $1250 \mathrm{gr}$ \\
magnesiumsulfate & $1250 \mathrm{gr}$ \\
potassiumnitrate & $2500 \mathrm{gr}$ \\
thymol & $300 \mathrm{gr}$ \\
phenol & 5 litre \\
formalin & 5 litre \\
glycerine & 2.5 litre \\
ethanol $96^{\circ}$ & 10 litre \\
water up to & 100 litre \\
\hline
\end{tabular}

B. Immersion solution (bath) in which the embalmed corpses are preserved for some weeks

\begin{tabular}{lc} 
formaline & 10 litre \\
phenol & 0.8 litre \\
ethanol $96^{\circ}$ & 80 litre \\
water up to & $+/-700$ litre \\
\hline
\end{tabular}




\section{Thiel method for embalming human corpses}

The new embalming technique (adapted from Thiel) ${ }^{1}$ is based on the use of a mixture of

4-chloro-3-methylenphenol,

as well as various salts for fixation,

boric acid for disinfecting and

ethylene glycol for preservation of tissue plasticity,

while the concentration of formalin is kept to the strict minimum $(0.8 \%)$

Two stem solutions are prepared (Thiel ${ }^{1}$ and Groscurth et al. ${ }^{3}$ )

A. Stem solution A

amounts for Endogent

boric acid 3\%

$1.9 \mathrm{~kg}$

(mono-)ethylene glycol 30\%

19 litre

ammonium nitrate 20\%

$12.6 \mathrm{~kg}$

potassium nitrate $5 \%$

$3.2 \mathrm{~kg}$

water

63.3 litre

Total

100 litre

\section{B. Stem solution B (chlorcresol)}

(mono-)ethylene glycol 10\% 18.2 litre

4-chloro-3-methylphenol 1\% $\quad 1.8 \mathrm{~kg}$

Total

20 litre

C. Embalming solution as a mix of stem A, stem B and additional products

stem solution A

14.3 litre

stem solution B

0.5 litre

formaline

0.3 litre

sodium sulphite

$0.7 \mathrm{~kg}$

Total

15.8 litre

Sodium sulphite and formaline are added just before perfusion. The final concentration of formaldehyde is less than $0.5 \%$. The cadavers are perfused by means of the great saphenous vein (if this vein is difficult to find or to inject, the femoral or carotid artery are used) with some 12 litres of this embalming solution.

\section{Immersion solution (bath)}

(mono-)ethylene glycol 10\%

71.9 litre

formaline $2 \%$

14.4 litre

stem solution B 2\%

14.4 litre

boric acid 3\%

$21.6 \mathrm{~kg}$

ammonium nitrate $10 \%$

$71.9 \mathrm{~kg}$

potassium nitrate $5 \%$

$36 \mathrm{~kg}$

sodium sulphite $7 \%$

$50 \mathrm{~kg}$

water

720 litre

Total

1000.2 litre

The bodies are stored for approximately 4-6 weeks in this immersion solution.

Thereafter the bodies are kept at about $4-6^{\circ} \mathrm{C}$ in vacuum in sealed plastic tubular sheets (otherwise mummification appears as brown spots on the skin).

The cadavers may be used for months up to approximately one year.

A good preservation of the tissue depends on a special know-how necessitating a tight collaboration with an anatomy department, as is the case for Swissendos ${ }^{2}$ and for Endogent.

Advantages we met with are the nearly natural aspect of tissues -it is a simulation of a life model-; there is a high mobility of joints and organs; bodies can be inflated and ventilated; no rigor occurs; virtually no coagulation of blood in large vessels is present; there is very low toxicity for the environment; no development of moulds occur; bacteriological disinfection is very effective.

Minus we met with is the higher cost of the Thiel embalming method products than of the products of the conventional method; the risk of mummification of hands and feet is higher, therefore a $4^{\circ} \mathrm{C}$ vacuum conservation is needed; more desquamation and bullae in the skin are seen when the body is disposed to the air; these bodies are not suitable for dissection during several days or weeks. 


\section{Results and Discussion}

\section{Set-up for Endogent workshops}

\section{Workstations:}

About six workstations can be set up in the dissection room. We count for about 110 set-ups each year, divided into several workshops. Each station consists of a dissection table and a video tower for laparoscopic, thoracic surgery and interventional techniques. One station is equipped with a camera for demonstrations through internet, in a conference room or auditorium (college room).

\section{Dossier:}

The Thiel cadavers can be used for several times: through a system of dossiers for each cadaver all interventions are noted and so we know exactly for which sections a cadaver can still be used. As far as possible first less invasive interventions are done; open surgical interventions, in which more tissues are damaged, are usually done at last.

\section{Accompaniment:}

Expert clinicians work as tutors and give intensive instructions before the participants start with the handson surgery. The groups are kept small to facilitate practical work for each participant and to give everyone the opportunity to do the intervention him/herself.

\section{Results of the Thiel embalming technique and possibilities for Endogent}

\section{In general after Thiel embalming:}

The procedure results in well preserved organs and tissues concerning colour, consistency, natural flexibility, natural plasticity and transparency. Tissues are more recognisable. Low-odour embalming preservation is a fact. This technique results in high standards of preservation with good disinfecting efficacy and without releasing harmful substances into the environment. This technique gives us a compromise between fixation and the in vivo condition/appearance.
But the cadavers can only be used for a short time and must be taken to the refrigerator vacuum packed after each workshop.

\section{Specific possibilities for applications for Endogent:}

The peritoneal cavity can be inflated for laparoscopic procedures.

Concerning thoracic surgery and thoracoscopy, it is possible now to practice/exercise interventions such as by-pass operations. Also dissection and placement of a by-pass around the arteries of the lower limb and abdominal arteries are possible.

The lung structure is very well preserved: another feature of the embalming procedure is the fact that the lungs can be ventilated during surgical procedures. And also endoscopical endobronchial techniques and bronchoscopy for investigation and treatment through the trachea are anyway perfectly possible.

Preliminary findings seem to indicate that the corpses also serve as a suitable phantom for assessing thorax radiological equipment.

Concerning orthopaedics also the articular joints approximate those of a living patient: the structures feel supple and normal. The joints remain freely movable. Already some orthopaedic workshops have passed: the embalmed bodies are excellently suitable for training all kinds of arthroscopic interventions and open surgery.

Up to now this cadaver model was used in our institute for laparoscopic bariatric surgery, colon and colorectal surgery, open gastro-enterological surgery, arthroscopy (orthopaedic), thorax surgery (cardiology) and endoscopic gynecological interventions.

We now try out the use of the special techniques from Thiel ${ }^{4}$ for fixation of the central nervous system in order to use Thiel embalmed corpses for neurosurgery.

\section{Extension to undergraduate medical students in the future}

We intend to expose also our undergraduate medical students (2nd and 3rd year) to demonstrations of surgical approaches on Thiel embalmed corpses, in order to 
reveal the need for detailed anatomical knowledge in the clinic at an early stage in the medical curriculum.

Some years ago, after the implementation of a new integrated system-based medical curriculum at our faculty with an important reduction of practical teaching hours, we have reorganized human gross anatomy practical courses to enhance 3D knowledge; we were imposed by the need for maximal efficiency of gross anatomy teaching in the dissecting room. Active selflearning practical courses are introduced on prosected preparations and models, through demonstrations of some regions and dissection sessions. We also focus on the anatomy of the living person, making use of medical imaging documents and of surface anatomy.

The recently introduced Thiel embalming method gives us endoscopic approaches of cadavers as a new tool to teach anatomy, in addition to dissections and prosections. Through endoscopy and the video tower the students can participate in demonstrations of thoracic, abdominal and arthrologic topographic anatomy. Also for this reason one station is equipped with a camera for demonstrations through internet, in a conference room or auditorium (college room).

\section{Conclusion}

Thus the cadavers can be used for training of both conventional and new surgical procedures, including laparoscopy, surgery of thorax, abdomen, and pelvis, as well as arthroscopy. As also Groscurth et al. ${ }^{3}$ wrote: "Hands-on anatomical training courses, as organized by the Swiss Institutes, using newly established techniques for embalming have been found to be very helpful in postgraduate training of ongoing specialists. The courses reflect just part of the clinical reality and therefore have a virtual character, but they prepare the clinicians for the daily work and thus improve the quality of postgraduate training. In this context cooperation between anatomists and clinicians is absolutely necessary and plays an important role for the future.

Improvements allow courses to provide students with more realistic simulations of both established and experimental surgical methods. Through these changes the value of in depth gross anatomy is enhanced as a topic of fundamental importance for the postgraduate medical and surgical curriculum".

\section{Postgraduate medical students}

Thanks to Endogent one can exercise without any risks and ethically justified in a very realistic setting: pseudo-life-situations are created. The greatest trump of Endogent is that the study process removes from the living person to the cadaver, in vivo training without the need of a patient. A step between first training on an animal model and later on immediately on a patient is offered: training on human cadavers with almost the same qualities as living patients. The step to take from a human cadaver to a living patient is much smaller, what results in a considerable shortage of the study time.

\section{Undergraduate medical students}

Through the study of anatomy on CT or MR images and the endoscopic approach the students will be convinced of the need for detailed knowledge of anatomy in a clinical setting. These teaching methods allow better 3D-impression and facilitation of recognition of structures and topographical relationships.

Compared to time-consuming dissections of the concerned regions without immediate link to medical imaging and without endoscopy, as organised in the old curriculum, students will be more motivated to study the prosected material or to perform dissections.

We found the appropriate proportion for an effective anatomy training program: imaging, living anatomy and endoscopy in the future reveals the clinical relevance and need to study 3D gross anatomy in the dissecting room through models and cadaver material.

\section{Acknowledgments}

The industrial companies Olympus (Hamburg) and Johnson \& Johnson Medical N.V./S.A. sponsor the facility by providing surgical instruments as well as funding. We thank the Educational Committee of Medicine of the University of Ghent for financial support. 
Special thanks go to our prosectors Aron De Smet and Hubert Stevens for their excellent work in embalming the human bodies and preparing the workshops.

\section{References}

1. Thiel W. Die Konservierung ganzer Leichen in natürlichen Farben. Ann Anat 1992; 174: 185-95.
2. Morand P, Fresard I, Chanson C, Rager G, Krähenbühl L. Endoscopic and thoracoscopic training on Thiel human cadavers: a model to teach advanced procedures. Chest Meeting Abstracts 2005 128: 310S-c-311S-c.

3. Groscurth P, Eggli P, Kapfhammer J, Rager G, Hornung JP, Fasel JDH. Gross Anatomy in the surgical curriculum in Switserland: improved cadaver preservation, anatomical models, and course development. Anat Rec (New Anat) 2001; 265: 254-6.

4. Thiel W. Ergänzung für die Konservierung ganzer Leichen nach W. Thiel. Ann Anat 2002; 184: 267-9.

\footnotetext{
Correspondence to: Ingrid Kerckaert, PhD Anatomie en Embryologie, UZ Gent, 4B3, De Pintelaan 185, B-9000 Gent, Belgium Phone: +32 93324855; Fax: +32 93323809 e-mail: ingrid.kerckaert@UGent.be Conflict of interest statement: No conflicts declared.
} 